\title{
Pseudochelin A, a siderophore of Pseudoalteromonas piscicida S2040
}

Sonnenschein, Eva; Stierhof, Marc; Goralczyk, Stephan; Vabre, Floriane M.; Pellissier, Leonie; Hanssen, Kine Østnes; de la Cruz, Mercedes; Díaz, Caridad; de Witte, Peter; Copmans, Daniëlle

Total number of authors:

20

Published in:

Tetrahedron

Link to article, DOI:

10.1016/j.tet.2017.03.051

Publication date:

2017

Document Version

Peer reviewed version

Link back to DTU Orbit

Citation (APA):

Sonnenschein, E., Stierhof, M., Goralczyk, S., Vabre, F. M., Pellissier, L., Hanssen, K. Ø., de la Cruz, M., Díaz, C., de Witte, P., Copmans, D., Andersen, J. H., Hansen, E., Kristoffersen, V., Tormo, J. R., Ebel, R., Milne, B. F., Deng, H., Gram, L., Jaspars, M., \& Tabudravu, J. N. (2017). Pseudochelin A, a siderophore of

Pseudoalteromonas piscicida S2040. Tetrahedron, 73(18), 2633-2637. https://doi.org/10.1016/j.tet.2017.03.051

\section{General rights}

Copyright and moral rights for the publications made accessible in the public portal are retained by the authors and/or other copyright owners and it is a condition of accessing publications that users recognise and abide by the legal requirements associated with these rights.

- Users may download and print one copy of any publication from the public portal for the purpose of private study or research.

- You may not further distribute the material or use it for any profit-making activity or commercial gain

- You may freely distribute the URL identifying the publication in the public portal 


\section{Graphical Abstract}

\section{Pseudochelin A, a siderophore of Pseudoalteromonas piscicida S2040 \\ Leave this area blank for abstract info.}

Eva C. Sonnenschein ${ }^{\mathrm{a} \dagger}$, Marc Stierhof ${ }^{\mathrm{b} \dagger}$, Stephan Goralczyk ${ }^{\mathrm{b}}$, Floriane M. Vabre ${ }^{\mathrm{b}}$, Leonie Pellissier ${ }^{\mathrm{b}}$; Kine Østnes Hanssen $^{\mathrm{d}}$, Mercedes de la Cruz ${ }^{\mathrm{e}}$, Caridad Díaz ${ }^{\mathrm{e}}$, Peter de Witte ${ }^{\mathrm{c}}$, Daniëlle Copmans ${ }^{\mathrm{c}}$, Jeanette Hammer Andersen ${ }^{\mathrm{d}}$, Espen Hansen ${ }^{\mathrm{d}}$, Venke Kristoffersen ${ }^{\mathrm{d}}$, José R. Tormo ${ }^{\mathrm{e}}$, Rainer Ebel ${ }^{\mathrm{b}}$, Bruce F. Milne ${ }^{\mathrm{f}}$, Hai Deng ${ }^{\mathrm{b}}$, Lone Gramª Marcel Jaspars ${ }^{\mathrm{b}}$, Jioji N. Tabudravu ${ }^{\text {b* }}$

${ }^{a}$ Technical University of Denmark, Department of Biotechnology and Biomedicine, Matematiktorvet 301, 2800 Kgs. Lyngby, Denmark.

${ }^{\mathrm{b}}$ Marine Biodiscovery Centre, Department of Chemistry, University of Aberdeen, Aberdeen AB24 3UE, Scotland, UK.

'Laboratory for Molecular Biodiscovery, Department of Pharmaceutical and Pharmacological Sciences KU Leuven Campus Gasthuisberg, O\&N II Herestraat 49, Box 824, 3000 Leuven, Belgium.

${ }^{d}$ Marbio, UiT The Arctic University of Norway, Breivika, Tromsø, Norway.

${ }^{e}$ Fundación MEDINA, Centro de Excelencia en Investigación de Medicamentos Innovadores en Andalucía, Avenida del Conocimiento 34, Parque Tecnológico de Ciencias de la Salud, 18016 Armilla, Granada, Spain.

${ }^{f}$ CFisUC, Department of Physics, University of Coimbra, Rua Larga, 3004-516, Coimbra, Portugal.

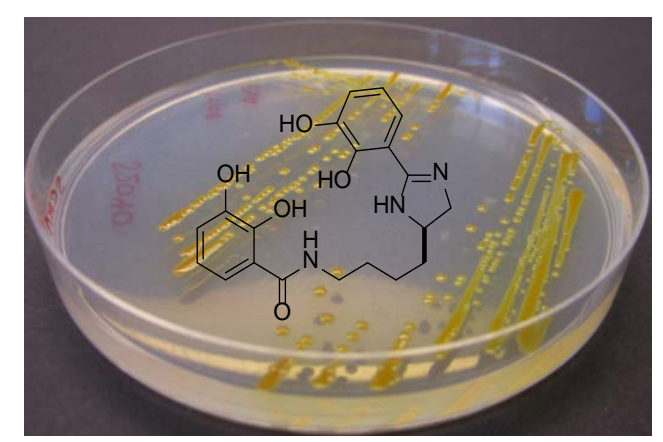




\section{Pseudochelin A, a siderophore of Pseudoalteromonas piscicida S2040}

Eva C. Sonnenschein ${ }^{\mathrm{a} \dagger}$, Marc Stierhof ${ }^{\mathrm{b}}{ }^{\dagger}$, Stephan Goralczyk ${ }^{\mathrm{b}}$, Floriane M. Vabre ${ }^{\mathrm{b}}$, Leonie Pellissier ${ }^{\mathrm{b}}$, Kine Østnes Hanssen $^{\mathrm{d}}$, Mercedes de la Cruz ${ }^{\mathrm{e}}$, Caridad Díaz ${ }^{\mathrm{e}}$, Peter de Witte ${ }^{\mathrm{c}}$, Daniëlle Copmans ${ }^{\mathrm{c}}$, Jeanette Hammer Andersen ${ }^{\mathrm{d}}$, Espen Hansen ${ }^{\mathrm{d}}$, Venke Kristoffersen ${ }^{\mathrm{d}}$, José R. Tormo ${ }^{\mathrm{e}}$, Rainer Ebel ${ }^{\mathrm{b}}$, Bruce F. Milne ${ }^{\mathrm{f}}$, Hai Deng ${ }^{\mathrm{b}}$, Lone Gram ${ }^{\mathrm{a}}$, Marcel Jaspars $^{\mathrm{b}}$, Jioji N. Tabudravu ${ }^{\mathrm{b} *}$

${ }^{a}$ Technical University of Denmark, Department of Biotechnology and Biomedicine, Matematiktorvet 301, 2800 Kgs. Lyngby, Denmark.

${ }^{\mathrm{b}}$ Marine Biodiscovery Centre, Department of Chemistry, University of Aberdeen, Aberdeen AB24 3UE, Scotland, UK.

${ }^{\mathrm{C}}$ Laboratory for Molecular Biodiscovery, Department of Pharmaceutical and Pharmacological Sciences, KU Leuven Campus, Gasthuisberg, O\&N II Herestraat 49, box 824, 3000 Leuven, Belgium.

${ }^{\mathrm{d}}$ Marbio, UiT The Arctic University of Norway, Breivika, Tromsø , Norway.

e Fundación MEDINA, Centro de Excelencia en Investigación de Medicamentos Innovadores en Andalucía, Avenida del Conocimiento 34, Parque Tecnológico de Ciencias de la Salud, 18016 Armilla, Granada, Spain.

${ }^{\mathrm{f}}$ CFisUC, Department of Physics, University of Coimbra, Rua Larga 3004-516, Coimbra, Portugal.

\section{ARTICLE INFO}

Article history:

Received

Received in revised form

Accepted

Available online

\section{Keywords:}

Pseudoalteromonas

Siderophore

Pseudochelin A

NMR

LCMS

\section{ABSTRACT}

A new siderophore containing a 4,5-dihydroimidazole moiety was isolated from Pseudoalteromonas piscicida S2040 together with myxochelins A and B, alteramide A and its cycloaddition product, and bromo- and dibromoalterochromides. The structure of pseudochelin A was established by spectroscopic techniques including 2D NMR and MS/MS fragmentation data. In bioassays selected fractions of the crude extract of S2040 inhibited the opportunistic pathogen Pseudomonas aeruginosa. Pseudochelin A displayed siderophore activity in the chrome azurol S assay at concentrations higher than $50 \mu \mathrm{M}$, and showed weak activity against the fungus Aspergillus fumigatus, but did not display antibacterial, anti-inflammatory or anticonvulsant activity.

2016 Elsevier Ltd. All rights reserved.

\footnotetext{
* Corresponding author. Tel.: +44-1224-273105; fax: +44-1224-272921; j.tabudravu@abdn.ac.uk
}

${ }^{\dagger}$ These authors contributed equally to this work 


\section{Introduction}

The element iron is an essential nutrient for growth of most microorganisms as it is required for important biological processes such as nitrogen fixation, amino acid synthesis, respiration, photosynthesis, DNA biosynthesis, and the citric acid cycle.[1] However, it occurs at very low levels in most natural environments, and the concentration for instance is below 0.5 $\mathrm{nM}$ in oceanic oxygenated waters at $\mathrm{pH}$ 7.[2] In order to obtain sufficient iron for their physiological needs most microorganisms have evolved biosynthetic strategies to cope with this deficiency. One of these is the production of siderophores,[3] which are small molecular weight chelating molecules that can help transport the insoluble iron $\left(\mathrm{Fe}^{3+}\right)$ into the cell via cell membrane specific receptor proteins.[1] Once inside the cell the complexed iron $^{3+}$ is released via reduction, ligand exchange or hydrolytic mechanisms[4] to $\mathrm{Fe}^{2+}$ soluble species.

There are three known classes of iron chelating moieties: phenols and catechols as in enterobactins,[5] hydroxamates ( $\mathrm{N}$ $\mathrm{OH}$ amides) as in the desferrioxamines,[6,7] and $\alpha$ hydroxycarboxylic acids as in achromobactin.[8,9] A closer look at these structures shows the presence of a high number of oxygen groups that can form ligands with positively charged cations. Oxygen ligands are well known for their high affinity for iron (III) species which has possibly resulted in the evolutionary selection of these groups by the microbial biosynthetic machinery.[10] In most of the cases, each ligand is an $\mathrm{OO}^{\prime}$ donor and each of the siderophores is able to form tris $\mathrm{OO}^{\prime}$ coordination to form the stable octahedral complex of the ferric ion.[1,10]

There are not many marine derived siderophores known compared to terrestrial ones. So far, the majority of the structures belong to a family of amphiphilic compounds containing an iron(III)-binding headgroup that is appended by a series of fatty acids.[1,11] The headgroup either contains a small peptide between 4-7 amino acids as in the amphibactins[12] or the $\alpha$ hydroxycarboxylic acid moiety in the form of an $\beta$ hydroxyaspartic acid or citric acid as in the case of the synechobactins.[13] Many microbes produce only one type of siderophore but, many, particularly infectious pathogenic ones[14,15] are known to produce multiple siderophores, including mixed-type ligands[16] as exemplified by the mycobactins that contain catechol, hydroxyamine and oxazole units.[17] Others contain thiazole as exemplified by pyochelin.[18] These features are believed to offer advantages to the microorganisms in their ability to evade the host response to continue sequestering iron from their environment in order to survive.[17,19] Furthermore, siderophores have been known to inhibit the growth of various phytopathogenic fungi such as Phytophthora parasitica,[20] Phythium ultimum,[21] and Fusarium oxysporum f.sp.dianthi.[22]
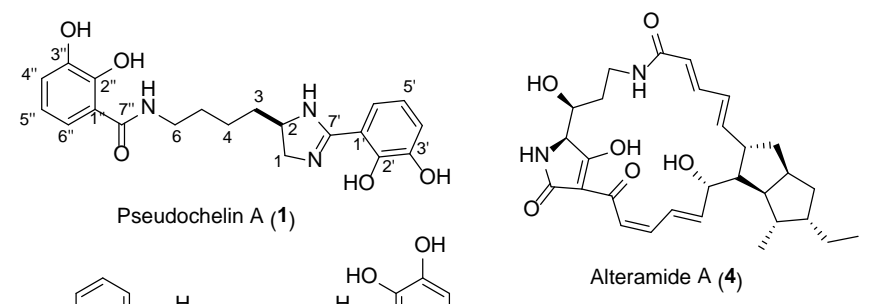<smiles>[R]CC(CCCCNC(=O)c1cccc(O)c1O)NC(=O)c1cccc(O)c1O</smiles>

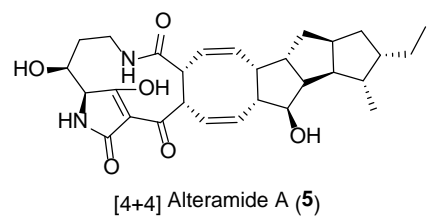

$\mathrm{R}=\mathrm{OH}$, Myxochelin A (2) $\mathrm{R}=\mathrm{NH}_{2}$, Myxochelin $\mathrm{B}(\mathbf{3})$

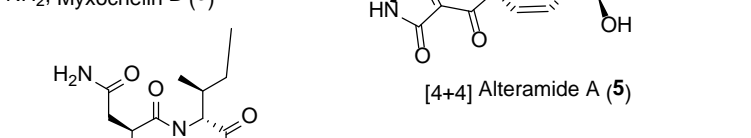

We report herein the isolation and structure elucidation of a new mixed-ligand siderophore, pseudochelin A (1) containing catechols and a 4,5-dihydro-imidazole moiety. Interestingly, we also isolated the known compounds myxochelins A and B that have been known to be produced only by myxobacteria.[23] Additionally, the known compound alteramide $\mathrm{A}$ and its [4+4]cyclo-addition product A were also isolated.[24] Finally, dereplication by LCMS and proton NMR also suggested the presence in the extracts of mono and dibromoalterochromides.[25] The presence of three different classes of compounds demonstrates the wide biosynthetic capability of this strain.

\section{Results and Discussion}

The crude extract of the culture of Pseudoalteromonas piscicida S2040 was fractionated by reversed phase solid phase extraction (SPE) before further purification by reversed phase HPLC to yield pseudochelin A (1) and six known compounds (27). The known compounds were identified by ${ }^{1} \mathrm{H}$ NMR, HRESIMS, and MS/MS data. Pseudochelin A (1) showed a high resolution ESIMS of $\mathrm{m} / \mathrm{z} 386.172[\mathrm{M}+\mathrm{H}]^{+}(\Delta 0.5 \mathrm{ppm})$ from calculated for $\mathrm{C}_{20} \mathrm{H}_{24} \mathrm{~N}_{3} \mathrm{O}_{5}$ and requiring 11 degrees of unsaturation. Interpretation of ${ }^{1} \mathrm{H}, \mathrm{HMBC}$ and edited HSQC NMR spectra (Figure S1-S4) of compound $\mathbf{1}$ indicated the presence of five methylenes, seven methines and eight quaternary carbons leading to the sub-formula $\mathrm{C}_{20} \mathrm{H}_{17}$. The presence of six methines $\left(\delta_{\mathrm{c}} 119.9,119.8,118.7,118.2,118.1\right.$ and 117.2) and six quaternary carbons $\left(\delta_{c} 148.7,147.5,146.1,145.9,115.5\right.$ and 107.8) suggested the presence of two aromatic rings, which together with the presence of two additional quaternary carbons at $\delta_{\mathrm{c}} 170.1$ and $\delta_{\mathrm{c}} 163.1$ accounted for a total of 10 double bond equivalents. This suggested the presence of a third ring in the structure of 1 to complete the 11 degrees of unsaturation. Use of one- and two-dimensional NMR data enabled the construction of 4 substructures (Figure 1).

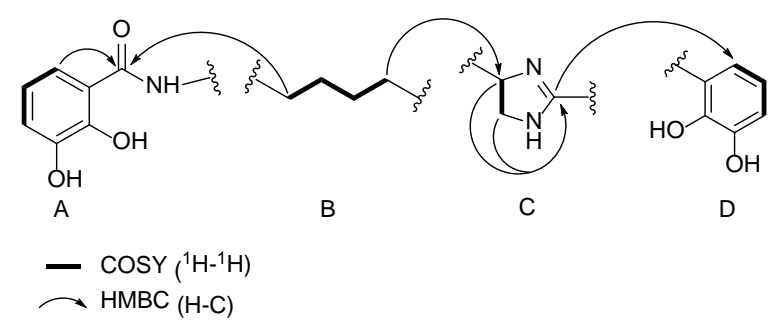

Figure 1. Substructure A-D of compound $\mathbf{1}$ with COSY and key HMBC correlations.

Inspection of the ${ }^{1} \mathrm{H}$ and ${ }^{13} \mathrm{C}$ NMR chemical shifts, ${ }^{1} \mathrm{H}-{ }^{1} \mathrm{H}$ coupling constants and COSY data suggested the presence of two similar, but isolated aromatic spin systems (substructures A and D, Figure 1) consistent with the presence of two catechol subunits. The adjacent units attached to these two systems however, were different. A HMBC correlation from $\delta_{\mathrm{H}} 7.18$ to $\delta_{\mathrm{C}} 170.1$ indicated the presence of an amide unit in substructure A. A more shielded quaternary carbon at $\delta_{\mathrm{C}} 163.0$ that correlated to the signal at $\delta_{\mathrm{H}} 7.14$ by HMBC suggested a different functional group was adjacent to substructure $D$. Long range HMBC correlations linked the proton signals at $\delta_{\mathrm{H}} 4.12 / 3.71, \delta_{\mathrm{H}} 4.36$ and $\delta_{\mathrm{H}} 7.14$ to the quaternary carbon signal $\delta_{\mathrm{C}} 163.0$ suggesting the presence of a 4,5-dihydro-imidazole unit (substructure C). The butyl chain was readily assigned by COSY and HMBC correlations (substructure B). The four substructures were assembled by long range HMBC correlations to give 
pseudochelin A (1) representing a new 4,5-dihydroimidazolecatechol-type siderophore.

Table 1

NMR data for pseudochelin $\mathrm{A}(\mathbf{1})$ in $\mathrm{CD}_{3} \mathrm{OD}$

\begin{tabular}{|c|c|c|c|c|}
\hline Pos. & $\delta_{\mathrm{C}}^{\mathrm{a}}$, type & $\delta_{\mathrm{H}^{\mathrm{b}}}^{\mathrm{b}}(\mathrm{J}$ in $\mathrm{Hz})$ & $\operatorname{COSY}\left({ }^{1} \mathrm{H}-{ }^{1} \mathrm{H}\right)$ & HMBC \\
\hline \multirow[t]{2}{*}{1} & $49.1, \mathrm{CH}_{2}$ & A: 4.12, dd $(11.6,11.2)$ & 2 & $2,3,7^{\prime}$ \\
\hline & & A:3.71, dd $(11.7,11.5)$ & 2 & $2,3,7^{\prime}$ \\
\hline 2 & 56.7, CH & 4.36, m & $1 \mathrm{~A}, 1 \mathrm{~B}, 3 \mathrm{~A}, 3 \mathrm{~B}$ & $1,7^{\prime}$ \\
\hline \multirow[t]{2}{*}{3} & $34.2, \mathrm{CH}_{2}$ & A: $1.86, \mathrm{~m}$ & $2,4 \mathrm{~A}, 4 \mathrm{~B}$ & 2 \\
\hline & & B: $1.77, \mathrm{~m}$ & $2,4 \mathrm{~A}, 4 \mathrm{~B}$ & 2 \\
\hline \multirow[t]{2}{*}{4} & 21.5, $\mathrm{CH}_{2}$ & A:1.52, $\mathrm{m}$ & $3 \mathrm{~A}, 3 \mathrm{~B}, 5$ & 5,6 \\
\hline & & $\mathrm{B}: 1.48, \mathrm{~m}$ & $3 \mathrm{~A}, 3 \mathrm{~B}, 5$ & 5,6 \\
\hline 5 & 28.8, $\mathrm{CH}_{2}$ & $1.70, \mathrm{~m}$ & $4 \mathrm{~A}, 4 \mathrm{~B}, 6$ & $3,4,6$ \\
\hline 6 & $38.5, \mathrm{CH}_{2}$ & $3.45, \mathrm{t}(6.9)$ & 5 & $4,5,7 "$ \\
\hline $1^{\prime}$ & 107.8, C & & & \\
\hline $2^{\prime}$ & 147.5, C & & & \\
\hline $3^{\prime}$ & 146.1, C & & & \\
\hline $4^{\prime}$ & 119.9, CH & 7.08, dd $(8.1,0.6)$ & $5^{\prime}$ & 2', 3', 6' \\
\hline $5^{\prime}$ & $119.8, \mathrm{CH}$ & 6.84 , dd $(8.1,8.1)$ & $4^{\prime}, 6^{\prime}$ & $1^{\prime}, 3^{\prime}$ \\
\hline $6^{\prime}$ & 118.7, CH & 7.14 , dd $(8.1,0.6)$ & $5^{\prime}$ & $\begin{array}{l}\text { 2', 4', 5', } \\
\text { 7', }\end{array}$ \\
\hline $7^{\prime}$ & 163.0, C & & & \\
\hline $1 "$ & 115.4, C & & & \\
\hline $2 "$ & 148.7, C & & & \\
\hline 3" & 145.9, C & & & \\
\hline $4 "$ & 118.1, CH & 6.91 , dd $(8.0,1.2)$ & $5 "$ & 2",3", 6" \\
\hline $5 "$ & $118.2, \mathrm{CH}$ & 6.70 , dd $(8.0,8.0)$ & 4", H6" & $1 ", 3 "$ \\
\hline $6 "$ & 117.2, CH & $7.18 \mathrm{dd}(8.0,1.2)$ & $5 "$ & $\begin{array}{ll}2 ", & 4 ", \\
5 ", 7 " & \end{array}$ \\
\hline 7" & $170.1, \mathrm{C}$ & & & \\
\hline
\end{tabular}

Coupling constants are in brackets and given in $\mathrm{Hz}$.

a $150 \mathrm{MHz}$

${ }^{\mathrm{b}} 400 \mathrm{MHz}$

Further supporting evidence of the structure came from MS/MS fragmentation data (Figure S6).

The absolute stereochemistry of compound $\mathbf{1}$ was determined to be $S$ by comparing the experimental circular dichroism spectrum with the theoretical spectrum calculated using self-interaction corrected time-dependent density functional theory within the real-space time-propagation framework (S1). The best fit was obtained between the experimental spectrum and the CD spectrum simulated for the $2 S$ configuration (Figure 2).

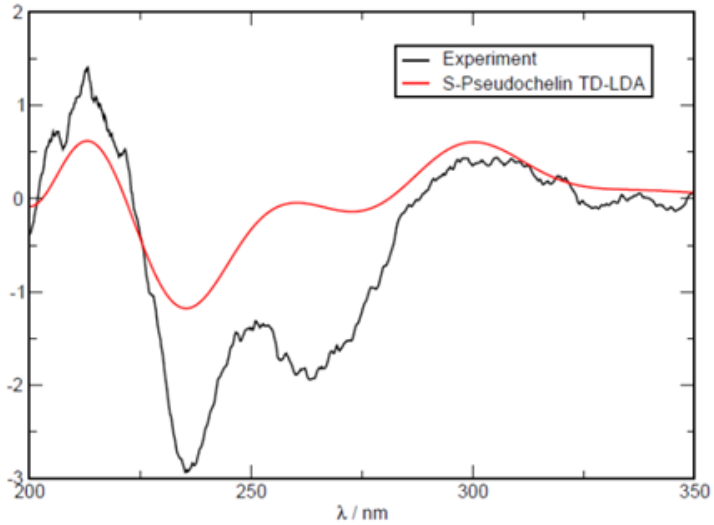

Figure 2. Experimental (black) and calculated (red) spectra of pseudochelin A (1).

Pseudochelin A can potentially exist in two tautomeric forms in solution as shown in Figure 3. Correlation of ${ }^{13} \mathrm{C}$ experimental and calculated chemical shift values did not show any significant difference between the two structures based on the regression coefficient values[26] (Figure 4).

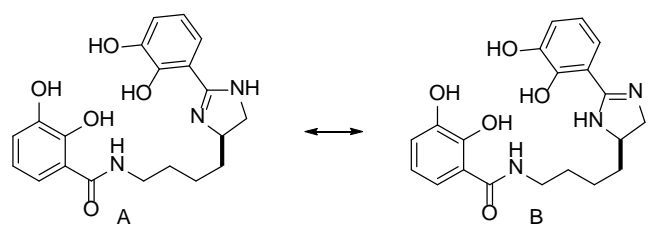

Figure 3. Tautomeric forms of pseudochelin A (1).

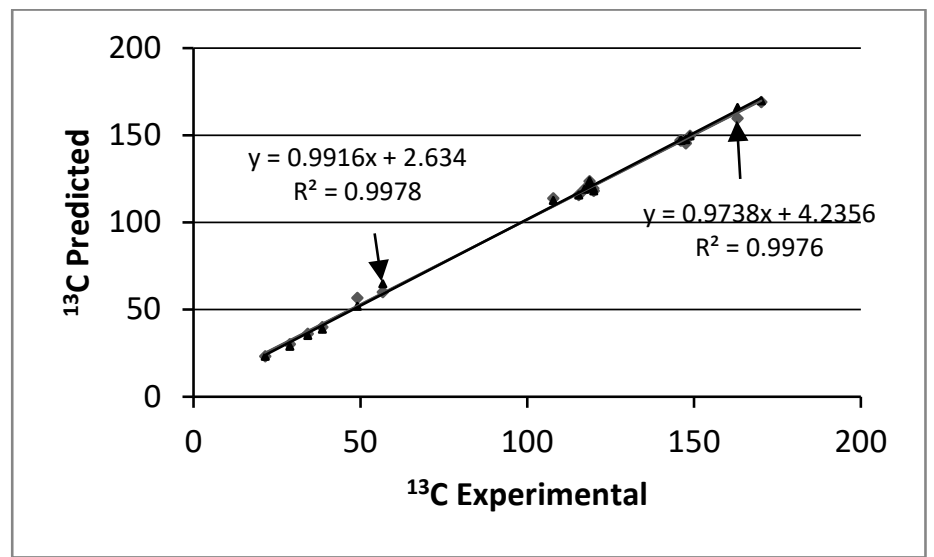

Figure 4. Experimental vs predicted ${ }^{13} \mathrm{C}$ data for the two tautomers of $\mathbf{1}$.

Pseudochelin A (1) complexes iron (III) as colour changes were observed after the addition of $\mathbf{1}$ to $\mathrm{Fe}^{3+}$ solutions (Figure S7), and the appearance of a broad absorption maximum at $572 \mathrm{~nm}$ in the UV spectrum in $\mathrm{MeOH}$ (Figures S8, S9). It also showed a HRESIMS $\mathrm{m} / \mathrm{z}$ of $439.0827(\mathrm{M}+\mathrm{H})^{+}(\Delta 0.4 \mathrm{ppm})$ from calculated for $\mathrm{C}_{20} \mathrm{H}_{21} \mathrm{~N}_{3} \mathrm{O}_{5} \mathrm{Fe}$ (Figure $\mathrm{S} 10$ ) suggesting three donor groups were involved in the formation of the ferric-pseudochelin $\mathrm{A}$ complex. The identity of these donor groups have not been determined yet even though any combination of three of the four catechol units is possible based on known binding mechanism of 
catechol-type siderophores.[3,27] Analogous compounds such as agrobactin and parabactin are known to utilize the nitrogen in the central oxazoline ring to form $\Lambda$, cis coordination compounds.[28] The metal biding properties of pseudochelin A is currently being investigated and will be discussed elsewhere.

Pseudochelin A is likely to originate from non-ribosomal peptide synthetase (NRPS) assembly line, a similar biosynthetic pathway to the one reported for myxochelins A and B,[23] where the aldehyde intermediate $\mathbf{2}$ is generated through the reduction of the peptidyl carrier protein (PCP)-bound thioester in the NRPS assembly line. The transamination on 2 yields myxochelin B (3) which can undergo cyclization to produce $\mathbf{1}$ (Scheme 1).

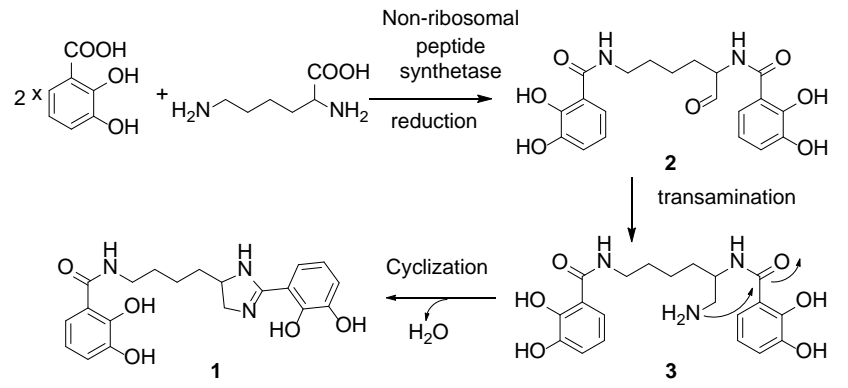
(1)

Scheme 1. Plausible biogenetic pathway of pseudochelin A

The four crude SPE fractions of Pseudoalteromonas piscicida S2040 were initially screened for antibacterial and antifungal activities. All fractions showed minor inhibitions (14-16\%) of Staphylococcus aureus MRSA-MB5393. The fraction (SPE 100) showed a $62 \%$ growth inhibition of Pseudomonas aeruginosa while the fraction (SPE 25) showed a minor inhibition (12\%) of Candida albicans MY1055. Pseudochelin A (1) was evaluated in these assays, but did not show any significant activity except for a weak antifungal activity against Aspergillus fumigatus ATCC46645 $\left(\mathrm{MIC}_{85}=32 \mu \mathrm{g} / \mathrm{mL}\right)$. Further evaluation of $\mathbf{1}$ in the anti-inflammatory, and the zebra-fish-assay for anticonvulsant or neurobehavioral activity showed no positive results.

In summary, we have discovered a new structure containing the 4,5-dihydroimidazole moiety with siderophore activity. Even though the role of the 4,5-dihydromimidazole in pseudochelin A in iron-chelation has not been determined, the structure shows similarity to other known 'mixed-ligand' class of siderophores exemplified by mycobactins[11], agrobactin[28], parabactin[28] vibriobactin[29,30], and pyochelin.[6,18] Mixed-ligands siderophores have attracted some attention about possible roles in virulence 'stealth' enabling their producers to avoid detections by the mammalian host defense mechanisms during cellular infections allowing them to continue sequestering iron from their host.[1,31-33] The results of biological assays have suggested that other compounds in the crude extract may be responsible for the observed activity against Pseudomonas aeruginosa as pseudochelin A did not show any antibacterial activity. The other compounds: myxochelin A, alteramides A, bromo- and dibromoalterochromides are known for their cytotoxicity activity.[24,25,34]

\section{Experimental section}

\subsection{General Experimental Procedures}

NMR data, both $1 \mathrm{D}$ and 2D were recorded on a Bruker AVANCE III HD spectrometer at 400 and $100 \mathrm{MHz}$ for ${ }^{1} \mathrm{H}$ and ${ }^{13} \mathrm{C}$ respectively in $\mathrm{CD}_{3} \mathrm{OD}$ (Cambridge Isotope Laboratories) using a $5 \mathrm{~mm}$ SmartProbe. High resolution mass spectrometry data were recorded using a Waters LCT Premier coupled to a Waters Acquity UPLC system, and a ThermoScientific LTQXLDiscovery Orbitrap coupled to an Accela HPLC system. The Waters LCT Premier MS system used the following conditions: capillary voltage $2600 \mathrm{~V}$, cone voltage $50 \mathrm{~V}$, desolvation temperature $350{ }^{\circ} \mathrm{C}$, desolvation gas $650 \mathrm{~L} / \mathrm{h}$, cone gas $5 \mathrm{~L} / \mathrm{h}$, mass range 150-1500 amu. The instrument was tuned to a resolution of 10,000 (FWHM) and leucine-enkephaline was used as lock mass for internal calibration. For the LTQXL-Discovery Orbitrap, the following conditions were used: capillary voltage $45 \mathrm{~V}$, capillary temperature $320^{\circ} \mathrm{C}$, auxiliary gas flow rate $10-20$ arbitrary units, sheath gas flow rate 40-50 arbitrary units, spray voltage $4.5 \mathrm{kV}$, mass range 100-2000 amu (maximum resolution 30,000). The optical rotation measurement was recorded using a Bellingham \& Stanley, Model ADP410 Polarimeter at $589 \mathrm{~nm}$. Semi-preparative HPLC purifications were performed on an Agilent 1100 HPLC system consisting of a solvent compartment, degasser, binary pump, autosampler, diode array detector (DAD) and a preparative fraction collector. The UV/Vis absorption of the pseudochelin A- $\mathrm{Fe}^{3+}$ complex was measured by HPLC using a Phenomenex HPLC C4 column ( 50 x $4.6 \mathrm{~mm}, 5 \mu \mathrm{m}, 300 \AA$ ) and using a linear gradient from 0 to $100 \%$ (MeOH in water) in 15 minutes. All solvents used in this study were either of HPLC or LCMS grade.

\subsection{Bacterial strain}

Pseudoalteromonas piscicida S2040 was isolated during the global research cruise Galathea 3 due to its bioactivity against the human pathogen Staphylococcus aureus NCTC 8325 and the fish pathogen Vibrio anguillarum 90-11-287 (serotype O1).[35] S2040 was obtained from a copepod sampled from surface water off the Northwestern coast of Australia (-16.06 N, 119.354 E).

\subsection{Culture}

S2040 was routinely grown on Marine Agar 2216 (MA) at $25^{\circ} \mathrm{C}$. For the initial screening, S2040 was pre-cultured overnight in $5 \mathrm{~mL}$ SCM (2\% sea salts (Sigma-Aldrich[36], S4), $0.3 \%$ casamino acids, $0.4 \%$ mannose) at $200 \mathrm{rpm}$ and $25^{\circ} \mathrm{C}$. A $500 \mathrm{~mL}$ baffled Erlenmeyer flask containing $150 \mathrm{~mL}$ SCM was inoculated with $750 \mu \mathrm{l}$ pre-culture and incubated at $200 \mathrm{rpm}$ and $25^{\circ} \mathrm{C}$. After 48 h, 1.8 g sterilized Diaion ${ }^{\circledR}$ HP-20 resin (SigmaAldrich) was added to the culture and incubation was continued for $24 \mathrm{~h}$.

Resin and cells were separated by centrifugation for $20 \mathrm{~min}$ at $3059 \mathrm{x}$ g. The resin was washed with MilliQ water and extracted with $\mathrm{MeOH}$. The cell pellet was extracted with EtOAc/MeOH $(8: 2, v / v)$, and combined with the resin extract. The crude extract was dried under nitrogen. Upscaling was performed accordingly in $2 \mathrm{~L} \mathrm{SCM}$ in $10 \mathrm{~L}$ Nalgene flasks and upon addition of $24 \mathrm{~g}$ Diaion ${ }^{\circledR}$ HP-20 resin (Sigma-Aldrich)[36]

\subsection{Fractionation and isolation}

The crude sample was fractionated on a C18 solid phase extraction (SPE) column using 25\% $\mathrm{MeOH}$ in water (SPE 25), followed by $50 \% \mathrm{MeOH}$ (SPE 50), then by $100 \% \mathrm{MeOH}$ (SPE 100). Finally, the column was flushed with $100 \%$ methanol containing $0.05 \%$ trifluoroacetic acid (SPE 100+TFA). The compounds of interest were detected in the SPE 50 fraction by LC-MS and ${ }^{1} \mathrm{H}$ NMR analysis. Purification of this fraction was 
carried out by reversed phase C18 HPLC using a mixture of $\mathrm{MeOH}$, water and TFA $(0.05 \%)$ as an eluent with a linear gradient from $0-100 \% \mathrm{MeOH}$ over $25 \mathrm{~min}$ and a solvent flow of $2 \mathrm{~mL} / \mathrm{min}$ to yield 1 (6.3 $\mathrm{mg}), 2$ (2.1 $\mathrm{mg})$ and 3 (2.5 $\mathrm{mg})$. Purification of the SPE 100 fraction was carried out by reversed phase C18 HPLC using a mixture of $\mathrm{MeOH}$ and water as eluent with a three step gradient from $60-80 \% \mathrm{MeOH}$ over $10 \mathrm{~min}$, followed by $80-100 \% \mathrm{MeOH}$ over $15 \mathrm{~min}$, and finally by $100 \%$ $\mathrm{MeOH}$ over $20 \mathrm{~min}$. In addition, the solvent flow rate was reduced from 2.0 to $1.4 \mathrm{~mL} / \mathrm{min}$ in the first step and then increased in the third step from 1.4 to $2.0 \mathrm{~mL} / \mathrm{min}$ to yield 4 (2.3 $\mathrm{mg}), 5$ (2.1 $\mathrm{mg}$ ) and a mixture of 6 and 7 (3.5 mg).

Pseudochelin A (1). Brownish oil, $6.3 \mathrm{mg} ;[\alpha]^{25}{ }_{\mathrm{D}}-51.3$ (с 1.01 $\mathrm{MeOH})$; IR $\left(\mathrm{cm}^{-1}\right)$ 3240, 2945, 2867, 1675, 1640, 1625, 1590, 1565, 1460, 1355, 1248, 1200, 1140, 840, 800, 725 (Figure S11); ${ }^{1} \mathrm{H}$ NMR and ${ }^{13} \mathrm{C}$ NMR (MeOD- $\delta_{4}$ ) see Table 2; HRESIMS $\mathrm{m} / \mathrm{z}$ $386.172[\mathrm{M}+\mathrm{H}]^{+}(\Delta 0.5 \mathrm{ppm})$ from calculated for $\mathrm{C}_{20} \mathrm{H}_{24} \mathrm{~N}_{3} \mathrm{O}_{5}$.

\subsection{Biological activities}

All the SPE fractions of S2040 were tested for their ability to inhibit the growth of Gram-negative and Gram-positive bacteria (Escherichia coli MB2884, Acinetobacter baumannii MB5973, Pseudomonas aeruginosa PAO-1, and methicillin-resistant Staphylococcus aureus MRSA, MB5393), fungi (Aspergillus fumigatus ATCC46645) and yeast (Candida albicans MY1055) following previously described methodologies.[37,38] Briefly, each compound was serially diluted in DMSO with a dilution factor of 2 to provide 10 concentrations starting at $64 \mu \mathrm{g} / \mathrm{mL}$ for all the assays. The MIC was defined as the lowest concentration of compound that inhibited $\geq 90 \%$ of the growth of a microorganism after overnight incubation. The Genedata Screener software[39] was used to process and analyze the data and also to calculate the RZ' factor, which predicts the robustness of an assay.[40] In all experiments performed in this work the RZ' factor obtained was between 0.87 and 0.98 .

Furthermore, the SPE fractions were tested for their antiinflammatory activity by inhibition of TNF $\alpha$ production in LPSstimulated monocytes (THP-1 cells) using sELISA.[41]

The pure compound pseudochelin A (1) was re-evaluated in all the above assays. The siderophore activity was performed using the chrome azurol S assay.[42] The zebrafish larvae assay for anticonvulsant activity was carried out using previously described methods (S2).

\section{Acknowledgements}

This work was supported by the EU seventh Framework Programme Project 'PharmaSea' (Grant agreement no. 312184). BFM acknowledges funding from the Portuguese Foundation for Science and Technology (CONT_DOUT/11/UC/405/10150/18/2008), and thanks DIPC and CFM (UPV/EHU) and the Laboratory for Advanced Computation (University of Coimbra) for support.

\section{Supplementary data}

Supplementary data (HRESIMS, MS/MS, UV, IR, and NMR including ${ }^{1} \mathrm{H},{ }^{13} \mathrm{C}$, COSY, HSQC and HMBC data of $\mathbf{1}$ associated with this article can be found in the online version..

\section{References and notes}

[1] M. Sandy, A. Butler, Chem. Rev. 109 (2009) 4580-4595.

[2] V. Vinatier, N. Wirgot, M. Joly, M. Sancelme, M. Abrantes, L. Deguillaume, A.-M. Delort, Environ. Sci. Technol. 50 (2016) 9315-9323.

[3] K.N. Raymond, C.J. Carrano, Acc. Chem. Res. 12 (1979) 183-190.

[4] M.E. Bluhm, S.S. Kim, E.A. Dertz, K.N. Raymond, J. Am. Chem. Soc. 124 (2002) 2436-2437.

[5] J.J. De Voss, K. Rutter, B.G. Schroeder, H. Su, Y. Zhu, C.E. Barry, Proc. Natl. Acad. Sci. 97 (2000) 1252-1257.

[6] N. Vinayavekhin, A. Saghatelian, ACS Chem. Biol. 4 (2009) 617-623.

[7] S. Dhungana, P.S. White, A.L. Crumbliss, JBIC J. Biol. Inorg. Chem. 6 (2001) 810-818.

[8] A.D. Berti, M.G. Thomas, J. Bacteriol. 191 (2009) 45944604.

[9] C.L. Smith, B.L. Weiss, S. Aksoy, L.J. Runyen-Janecky, Appl. Environ. Microbiol. 79 (2013) 2872-2881.

[10] M.J. Miller, F. Malouin, Acc. Chem. Res. 26 (1993) 241-249.

[11] E. Mawji, M. Gledhill, J.A. Milton, G.A. Tarran, S. Ussher, A. Thompson, G.A. Wolff, P.J. Worsfold, E.P. Achterberg, Environ. Sci. Technol. 42 (2008) 8675-8680.

[12] V.V. Homann, M. Sandy, J.A. Tincu, A.S. Templeton, B.M. Tebo, A. Butler, J. Nat. Prod. 72 (2009) 884-888.

[13] T. Ito, T. Odake, H. Katoh, Y. Yamaguchi, M. Aoki, J. Nat. Prod. 74 (2011) 983-988.

[14] M. Miethke, M.A. Marahiel, Microbiol. Mol. Biol. Rev. 71 (2007) 413-451.

[15] N. Li, C. Zhang, B. Li, X. Liu, Y. Huang, S. Xu, L. Gu, J. Biol. Chem. 287 (2012) 8912-8919.

[16] W.M. Wuest, E.S. Sattely, C.T. Walsh, J. Am. Chem. Soc. 131 (2009) 5056-5057.

[17] T.M. Hoette, R.J. Abergel, J. Xu, R.K. Strong, K.N. Raymond, J. Am. Chem. Soc. 130 (2008) 17584-17592.

[18] J. Brandel, N. Humbert, M. Elhabiri, I.J. Schalk, G.L.A. Mislin, A.-M. Albrecht-Gary, Dalton Trans. 41 (2012) 2820.

[19] T.M. Hoette, M.C. Clifton, A.M. Zawadzka, M.A. Holmes, R.K. Strong, K.N. Raymond, ACS Chem. Biol. 6 (2011) 1327-1331.

[20] S.S. Ali, N.N. Vidhale, Int J Curr Microbiol Appl Sci 2 (2013) 303-312.

[21] H. Hamdan, D.M. Weller, L.S. Thomashow, Appl. Environ. Microbiol. 57 (1991) 3270-3277.

[22] S. Buysens, K. Heungens, J. Poppe, M. Hofte, Appl. Environ. Microbiol. 62 (1996) 865-871.

[23] Y. Li, K.J. Weissman, R. Müller, J. Am. Chem. Soc. 130 (2008) 7554-7555.

[24] H. Shigemori, M.A. Bae, K. Yazawa, T. Sasaki, J. Kobayashi, J. Org. Chem. 57 (1992) 4317-4320.

[25] M. Speitling, O.F. Smetanina, T.A. Kuznetsova, H. Laatsch, J. Antibiot. (Tokyo) 60 (2007) 36-42.

[26] M. Elyashberg, A.J. Williams, K. Blinov, Nat. Prod. Rep. 27 (2010) 1296.

[27] M.E. Cass, T.M. Garrett, K.N. Raymond, J. Am. Chem. Soc. 111 (1989) 1677-1682.

[28] J.B. Neilands, T. Peterson, S.A. Leong, in:, A.E. Martell (Ed.), Inorg. Chem. Biol. Med., AMERICAN CHEMICAL SOCIETY, WASHINGTON, D.C., 1980, pp. 263-278.

[29] R.J. Bergeron, J.R. Garlich, J.S. McManis, Tetrahedron 41 (1985) 507-510.

[30] G.L. Griffiths, S.P. Sigel, S.M. Payne, J.B. Neilands, J. Biol. Chem. 259 (1984) 383-385.

[31] R.J. Abergel, A.M. Zawadzka, K.N. Raymond, J. Am. Chem. Soc. 130 (2008) 2124-2125.

[32] B.E. Allred, C. Correnti, M.C. Clifton, R.K. Strong, K.N. Raymond, ACS Chem. Biol. 8 (2013) 1882-1887. 
[33] R.J. Abergel, M.K. Wilson, J.E.L. Arceneaux, T.M. Hoette, R.K. Strong, B.R. Byers, K.N. Raymond, Proc. Natl. Acad. Sci. 103 (2006) 18499-18503.

[34] S. Schieferdecker, S. König, A. Koeberle, H.-M. Dahse, O. Werz, M. Nett, J. Nat. Prod. 78 (2015) 335-338.

[35] L. Gram, J. Melchiorsen, J.B. Bruhn, Mar. Biotechnol. 12 (2010) 439-451.

[36] Sigma-Aldrich (n.d.).

[37] J. Martín, T. da S. Sousa, G. Crespo, S. Palomo, I. González, J. Tormo, M. de la Cruz, M. Anderson, R. Hill, F. Vicente, O. Genilloud, F. Reyes, Mar. Drugs 11 (2013) 387-398.

[38] L. Zhang, A.S. Ravipati, S.R. Koyyalamudi, S.C. Jeong, N. Reddy, J. Bartlett, P.T. Smith, M. de la Cruz, M.C. Monteiro, Á. Melguizo, E. Jiménez, F. Vicente, Asian Pac. J. Trop. Med. 6 (2013) 673-681.

[39] (n.d.).

[40] J.H. Zhang, T.D. Chung, K.R. Oldenburg, J. Biomol. Screen. 4 (1999) 67-73.

[41] K. Lind, E. Hansen, B. Østerud, K.-E. Eilertsen, A. Bayer, M. Engqvist, K. Leszczak, T. Jørgensen, J. Andersen, Mar. Drugs 11 (2013) 2655-2666.

[42] B. Schwyn, J.B. Neilands, Anal. Biochem. 160 (1987) 47-56. 